Revue d'histoire de l'enfance « irrégulière »

Le Temps de l'histoire

2| 1999

Cent ans de répressions des violences à enfants

\title{
A propos des violences sexuelles à enfants
}

\section{Georges Vigarello et Jean-Jacques Yvorel}

\section{OpenEdition}

Journals

Édition électronique

URL : http://journals.openedition.org/rhei/37

DOI : $10.4000 /$ rhei. 37

ISBN : 978-2-7535-1639-7

ISSN : 1777-540X

Éditeur

Presses universitaires de Rennes

Édition imprimée

Date de publication : 15 novembre 1999

Pagination : 161-163

ISSN : 1287-2431

Référence électronique

Georges Vigarello et Jean-Jacques Yvorel, «A propos des violences sexuelles à enfants », Revue d'histoire de l'enfance « irrégulière » [En ligne], 2 | 1999, mis en ligne le 30 juillet 2010, consulté le 03 décembre 2020. URL : http://journals.openedition.org/rhei/37 ; DOI : https://doi.org/10.4000/rhei.37 


\section{À propos des violences sexuelles à enfants}

\section{Georges Vigarello}

Jean-Jacques Yvorel. Même si les violences sexuelles à l'égard des enfants commencent à être prises en compte au XVIIIe siècle, c'est principalement au XIXe siècle qu'elles acquièrent une spécificité et que la tolérance dont elles ont bénéficié recule. Pouvez-vous nous indiquez quelques étapes de ce lent processus?

Georges Vigarello. Nous pouvons prendre comme fil conducteur la réflexion et l'élaboration juridique. Le code pénal de 1810 est un moment clef de ce processus. Il institue en effet un nouveau crime : les violences exercées sur une personne "avec l'intention d'offenser sa pudeur". Nouveau barreau dans l'échelle des crimes et des délits, l'attentat à la pudeur permet que des gestes, qui jusque-là n'étaient pas relevés par la loi, deviennent punissables.

JJY. Et les enfants sont directement concernés par cette nouvelle incrimination?

GV. Oui, car si la victime est un enfant, alors même que la défloraison est attestée, le terme d'attentat à la pudeur l'emporte généralement sur celui de viol.

JJY. Comment expliquer ce choix des mots?

GV. La jurisprudence des premières décennies du XIXe siècle montre que médecins experts et juges estiment que la disproportion entre les organes sexuels d'un adulte et ceux d'un enfant rend impossible l'intromission du membre viril. Comme le modèle du viol reste l'accomplissement violent d'un acte sexuel complet avec son risque d'enfantement, pour les hommes de ce premier XIXe siècle, le viol sur un enfant n'existe pas. Cette position sous-entend aussi que les magistrats et les tribunaux adoptent la perspective de l'auteur; le viol est défini par la jouis- 
sance "normale" de l'assaillant et non par le ressenti de la victime.

JJY. En évitant le mot viol, l'acte paraît moins grave. Ce triomphe de l'euphémisme se traduit-il par une moindre sévérité?

GV. Par rapport à aujourd'hui, cet euphémisme traduit une façon différente de tolérer et de définir la souffrance de l'enfant mais il n'exclut pas une certaine sévérité, bien au contraire. Le pourcentage d'acquittements en matière d'attentat à la pudeur pour la période 1825-1831 est de $37 \%$. Il dépasse $50 \%$ pour tous les autres crimes.

JJY. Le travail juridique ne s'arrête pas au code de 1810 et à l'attentat à la pudeur?

GV. Non, bien sûr! Le travail initié par les hommes de 1789, qui consistait à distinguer toujours davantage les crimes pour mieux hiérarchiser les gravités, se poursuit. La révision du code pénal de 1832 est particulièrement importante, notamment en matière de crime sexuel.

Dans les années vingt du XIXe siècle, l'idée de viol ou d'attentat à la pudeur reste liée à l'usage de la force, de la brutalité. Les auteurs d'attentats à la pudeur commis sans violence physique sont acquittés, mais un lent travail juridique est déjà à l'œuvre. L'exemple du curé de Benfeld, en Alsace, est, sur ce point, significatif. Ce prêtre est accusé en 1827 d'attentat à la pudeur commis avec violence sur huit enfants du catéchisme. Son avocat plaide la "violence morale" et non la violence physique. Il a gain de cause; les faits sont reconnus, mais la cour leur dénie tout caractère criminel. Même si elle sert d'argument de défense, la catégorie "violence morale" fait son entrée dans le prétoire. Parallèlement, les commentateurs judiciaires, et notamment ceux de La Gazette des tribunaux, s'indignent et regrettent l'absence de toute disposition pénale pour réprimer les atteintes sexuelles sur enfants "non violentes". À l'occasion de la révision du code de 1832, le législateur prend en compte cette autre violence, même si le terme violence morale n'apparait pas dans la loi. En effet, les hommes de la Monarchie de Juillet préferent choisir un critère d'âge et considérer qu'au-dessous de 11 ans l'attentat à la pudeur, quel que soit sa forme, est une violence. L'article 311 stipule, dans sa nouvelle rédaction, que " tout attentat à la pudeur, consommé ou tenté sans violence sur la personne d'un enfant de l'un ou 
l'autre sexe âgé de moins de 11 ans, sera puni de réclusion ". La loi du 18 avril 1863 reporte de 11 à 13 ans cet âge au-dessous duquel tout attentat à la pudeur commis sur un enfant est présumé violent.

\section{JJY. Comment ce nouveau texte est-il appliqué?}

GV. Nous retrouvons l'euphémisation que nous évoquions précédemment. Ainsi, un canonnier est condamné en 1833 pour « attentat à la pudeur commis sans violence sur un enfant de moins de 11 ans». En fait, tout indique que la violence, exercée à l'égard d'une fillette âgée de 5 ans, est massive et sanglante. La peine encourue est, du fait de la qualification "sans violence", fortement atténuée, mais la sentence touche un militaire décoré qui, avant 1832, n’aurait sûrement pas été inquiété. De plus, nombre d'attentats commis sans violence ne sont pas considérés comme des crimes. À la fin du XIXe siècle, les rédacteurs de la Gazette des tribunaux s'insurgent contre les acquittements trop nombreux pour ce genre de crime. Les journalistes de la revue, qui le plus souvent appartiennent aux professions juridiques, prônent même la correctionnalisation de ces délits et l'utilisation de la qualification d'outrage à la pudeur pour que les auteurs d'agressions sexuelles sur mineur(e)s n'échappent pas à toute sanction.

\section{JJY. N'est-ce pas une pratique déjà largement mise en ouvre?}

GV. En effet. Depuis 1870 le principe du déclassement s'est banalisé. Cette correctionnalisation, qui permet d'éviter les "acquittements scandaleux", est aussi la marque de la résistance de la société à la prise en compte de ce type de violence à enfant. 